\title{
KAJIAN BEBERAPA ASPEK BIOLOGI REPRODUKSI IKAN KERAPU SEBAGAI ACUAN PEMILIHAN SPESIES POTENSIAL BUDIDAYA PERIKANAN PANTAI
}

\author{
Andi Marsambuana Pirzan*', Utojo ${ }^{*}$ dan Syarifuddin Tonnek*'
}

\begin{abstract}
ABSTRAK
Penelitian ini bertujuan untuk mengetahui hubungan antara ukuran panjang-bobot dengan tingkat dan indeks kematangan gonad, fekunditas dan diameter telur ikan kerapu serta kelimpahannya sebagai acuan dalam pemilihan spesies potensial budidaya perikanan pantai. Sampel ikan sebanyak 30 ekor dikumpulkan setiap bulan selama tujuh bulan di tempat pendaratan ikan (TPI) dan di pasar Barru dan Takkalasi (Kabupaten Barru), Kotamadya Parepare, dan Kabupaten Pangkajene Kepulauan. Sampel ikan yang terkumpul dibawa ke laboratorium untuk diidentifikasi dan diukur panjang dan bobot badannya. Gonad ikan diambil dan ditimbang kemudian dihitung jumlah telur dan diukur diameternya. Ikan kerapu yang dikumpulkan dan setelah dilakukan identifikasi terdiri atas 25 spesies tercakup ke dalam enam genera, yaitu Aethaloperca, Anyperodon. Cephalopholis, Epinephelus, Plectropomus, dan Variola. Jumlah telur terbanyak (1.298.988 butir) didapatkan pada Epinephelus areolatus bobot badan (BB) $1.600 \mathrm{~g}$ dan panjang total (PT) $49,5 \mathrm{~cm}$ dan terkecil (1.360 butir) pada $E$. quoyanus $(\mathrm{BB}=267.11 \mathrm{~g} ; \mathrm{PT}=26,7 \mathrm{~cm})$. Diameter telur terbesar $(494,18 \pm 82,32 \mu \mathrm{m})$ ditemukan pada Plectropomus leopardus $(\mathrm{BB}=200,15 \mathrm{~g}$; $\mathrm{PT}=25,4 \mathrm{~cm}$ ) dan terendah $(47,60 \pm 7,36 \mu \mathrm{m})$ pada $E$. taluina $(\mathrm{BB}=3.600 \mathrm{~g} ; \mathrm{PT}=64,3 \mathrm{~cm})$. Indeks kematangan gonad $(\mathrm{IKG})$ tertinggi $(6,25 \%)$ pada $E$. areolatus $(\mathrm{BB}=1.600 \mathrm{~g} ; \mathrm{PT}=49,5 \mathrm{~cm})$ dan terendah $(0.05 \%)$ pada $E$. tauvina $(\mathrm{BB}=3.600 \mathrm{~g} ; \mathrm{PT}=$ $64,3 \mathrm{~cm}$ ). Dihubungkan dengan kelimpahan populasi di alam, ukuran ikan, fekunditas, diameter telur dan IKG maka kerapu lumpur (E.tauvina), kerapu macan (E. fuscoguttatus), kerapu sunu $(P$. leopardus), dan kerapu bulucomba ( $E$. areolatus) memungkinkan untuk dikembangkan sebagai spesies potensial budidaya pantai.
\end{abstract}

\begin{abstract}
Study on reproductive biology of groupers in reference to potential species selection for coastal aquaculture. By: Andi Marsambuana Pirzan, Utojo, and Syarifuddin Tonnek

This study aimed to assess the relationship between fish size, gonad stage and somatic index, fecundity, egg diameter, and abundance of groupers as the way to select the potential species for coastal aquaculture. Fish samples of 30 individuals were collected every month from July 1996 to January 1998 at landing places (LP) and markets at Barru, Takkalasi, Parepare, and Pangkajene. The fish samples were identified and measured (body weight $=B W$ and total length $=T L$ ). Gonads were taken for determining gonadsomatic index (GSI), fecundity and egg diameter. The fish samples were identified and consisted of 25 species belonged to 6 genera i.e. Aethaloperca, Anyperodon, Cephalopholis, Epinephelus, Plectropomus, and Variola. The highest fecundity $(1,298,988$ eggs) was found in Epinephelus areolatus $(B W=1,600 \mathrm{~g} ; \mathrm{TL}=49,5 \mathrm{~cm})$ and the lowest $(1,360$ eggs) was in $E$. quoyanus $(B W=267.11 \mathrm{~g} ; T L=26.7 \mathrm{~cm})$. The biggest egg diameter $(494.18 \pm 82.32$ $\mu \mathrm{m})$ was in Plectropomus leopardus $(B W=200.15 \mathrm{~g} ; T L=24.5 \mathrm{~cm})$ and the smallest $(47.60 \pm 7.36$ $\mu \mathrm{m})$ was in E. tauvina $(B W=3.600 \mathrm{~g} ; T L=64.3 \mathrm{~cm})$. The highest $G S I(6.25 \%)$ was in $E$. areolatus $(B W=1,600 \mathrm{~g} ; T L=49.5 \mathrm{~cm})$ and the lowest $(0.05 \%)$ was in $E$. tauvina $(B W=3,600 \mathrm{~g} ; T L=64.3$ $(\mathrm{m})$. Based on the size, fecundity, egg diameter, GSI, and abundance of greasy grouper (E. tauvina), brown marbled ( $E$. fuscoguttatus), leopard coral grouper ( $P$. leopardus) and areolate grouper (E. areolatus), it was indicated that these species have good potential for coastal aquaculture.
\end{abstract}

KEYWORDS: reproductive biology, grouper, aquaculture, coastal waters.

\section{PENDAHULUAN}

Ikan kerapu termasuk famili Serranidae, subfamili Epinephelinae yang terdiri atas 15 genus, umumnya dikenal dengan nama grouper, rockcod, hind, dan seabass (Heemstra \& Randall,
1993). Kohno et al. (1990) telah mengidentifikasi 46 spesies ikan kerapu di perairan Filipina dan Indonesia yang tercakup ke dalam tujuh genera (Aethaloperca, Anyperodon, Cephalopholis, Cromileptes, Epinephelus, Plectropomus, dan Vari. ola).

\footnotetext{
Peneliti pada Balai Penelitian Perikanan Pantai. Maros
} 
Beberapa ikan kerapu bersifat androgynous hermaphrodite, yaitu mengalami perubahan kelamin dari jantan dalam siklus pertama matang gonad ke betina dalam siklus selanjutnya, seperti pada Epinephelus microdon (Debas et al., 1989 dalam Yashiro et al., 1993a). Sebaliknya terdapat pula yang bersifat protogynous hermaphrodite, artinya berubah kelamin dari betina ke jantan bila ukuran panjang telah mencapai lebih dari $50 \mathrm{~cm}$ atau bila bobot badan telah mencapai lebih dari 4 kg untuk genus Epinephelus seperti kerapu lumpur (E. suillus dan E. tauvina) dan kerapu macan (E. fuscoguttatus) (Ahmad et al., 1991). Kebanyakan ikan kerapu air payau adalah protogynous her. maphrodite. Pembedaan jenis kelamin ikan kerapu yang belum matang gonad dilakukan dengan jalan membedah ikan, sedangkan yang telah mencapai matang gonad dapat dilakukan dengan jalan stripping. Pejantan akan mengeluarkan cairan sperma berwarna putih susu dan induk betina mengeluarkan telur yang telah mengalami ovulasi. Perubahan kelamin ikan kerapu dari betina ke jantan atau sebaliknya dan pembedaan jenis kelamin merupakan problem dalam pengembangan diversifikasi spesies potensial budidaya.

Dalam pemilihan komoditas budidaya terdapat enam kriteria yang perlu diperhatikan, yaitu sifat dan kapasitas reproduksi, tabiat makan, laju pertumbuhan tinggi, serta kemampuan beradaptasi terhadap kepadatan yang tinggi, termasuk toleran terhadap perubahan kondisi lingkungan dan digemari konsumen (Kuo et al., 1988). Tujuan kajian aspek biologi reproduksi ikan kerapu (tingkat dan indeks kematangan gonad, fekunditas, diameter telur, jenis kelamin, dan ukuran dewasa kelamin) perlu diketahui dalam rangka pengembangan diversifikasi spesies potensial budidaya dan pengelolaan sumber daya ikan kerapu.

\section{BAHAN DAN METODE}

Pengumpulan sampel ikan dilakukún secara acak sederhana di pantai Barru, Parepare dan Pangkep. Pengambilan sampel sebanyak 30 ekor per bulan dilakukan di tempat pendaratan ikan (TPI) dan di pasar-pasar.

Sampel ikan kerapu dibawa ke laboratorium, diawetkan dengan formalin $10 \%$, selanjutnya diidentifikasi berdasarkan Kohno et al. (1990) dan Heemstra \& Randall (1993) dengan memperhatikan warna, ukuran, bentuk, dan warna bintik yang menutupi tubuh ikan, bentuk tubuh, perbandingan antara panjang kepala dan panjang standar ikan, serta jumlah dan bentuk sirip (punggung, dada, perut, dubur, dan ekor) setiap genus ikan.

\section{Ciri-ciri identifikasi adalah:}

Aethaloperca: genus merupakan monotipik, terdiri atas satu spesies, warna cokelat gelap, tubuh melebar, sirip dada tidak simetris, sirip punggung terdiri atas sembilan jari-jari keras, sirip ekor tegak.

Anyperodon: genus merupakan monotipik, warna abu-abu sampai abu-abu kecoklatan, bintik cokelat pada kepala, tidak ada gigi pada langit-langit, kepala dan tubuh memanjang, tinggi badan $11-15 \%$ dari panjang standar dan 3.4 kali panjang kepala, sirip ekor membundar.

Cephalopholis: warna gelap, yaitu coklat kemerahan sampai coklat tua sedangkan warna terang, yaitu merah kecoklatan sampai merah atau kuning atau jingga, panjang kepala 2,2-3,1 kali panjang standar, rahang pada ikan dewasa di. lengkapi dengan bonggol, sirip ekor membundar.

Epinephelus: tubuh ditutupi dengan bintikbintik berukuran sedang berwarna coklat atau kuning, merah bahkan warna putih, tinggi badan pada permulaan sirip punggung .biasanya lebih tinggi dibanding dengan di pangkal sirip dubur, sirip ekor biasanya membundar (beberapa spesies berbentuk tegak tetapi jarang berlekuk).

Plectropomus: warna gelap bergaris (menyerupai pita) bahkan ada yang tidak bergaris, warna tubuh agak keputihan, sirip berwarna kuning, tulang sirip dubur lemah, panjang kepala 2,8-3,1 kali panjang standar, sirip ekor umumnya berbentuk tegak.

Variola: tubuh berbintik merah, sirip ekor berwarna putih tipis pada bagian pinggir, panjang kepala 2,5-2,8 kali panjang standar, sirip ekor bentuk sabit.

Sampel ikan diukur panjang dan bobot masing. masing dengan menggunakan mistar dengan ketelitian $0,1 \mathrm{~cm}$ dan timbangan listrik dengan ketelitian 0,1 mg. Gonad ikan diambil dan ditimbang. Tingkat kematangan gonad (TKG) serta indeks kematangan gonad (IKG) diidentifikasi dengan berpedoman pada Yashiro et al. (1993a) dengan rumus:

$$
\mathrm{I} \mathrm{KG}=\frac{\mathrm{Bg}}{\mathrm{Bi}} \times 100 \%
$$

$\mathrm{IKG}=$ Indeks Kematangan Gonad

$\mathrm{Bg}=$ Bobot $\operatorname{gonad}(\mathrm{g})$

$\mathrm{Bi}=$ Bobot ikan $(\mathrm{g})$ 
Fekunditas dihitung dengan menggunakan metode gravimetri. Subsampel gonad diambil pada bagian depan, tengah, dan belakang masing. masing dengan bobot $0,05 \mathrm{~g}$. Fekunditas dari satu gonad dihitung berdasarkan rumus:

$$
\mathrm{Ft}=\frac{\mathrm{Jts}}{\mathrm{Bst}} \mathrm{Btt}
$$

$\mathrm{Ft}=$ Fekunditas total

Jts =Jumlah telur subsampel

Btt $=$ Bobot total telur $(\mathrm{g})$

Bst $=$ Bobot subsampel telur $(\mathrm{g})$

Diameter telur diukur dengan mengamati 100 butir dari setiap sampel gonad dengan menggunakan mikroskop yang dilengkapi dengan mikrometer okuler.

\section{HASIL DAN PEMBAHASAN}

Ikan kerapu yang dikumpulkan setiap bulan mulai bulan Juli 1996 sampai dengan Januari 1997 sejumlah 159 ekor ternyata terdiri atas enam genera yang mencakup 25 spesies, yaitu Aethaloperca (A. rogaa), Anyperodon (A. leucogrammicus), Cephalopholis (C. argus, C. aurantia, C. boenak, C. cyanostigma, C. leopardus, C. miniata, C. sexmaculata, dan C. sonnerati), Epinephelus ( $E$. areolatus, E. bleekeri, E. collaricola, E. fuscoguttatus, E. merra, E. microdon, E. ongus, E. quoyanus, E. suillus, dan E. tauvina), Plectropomus (P. laevis, P. leopardus, P. maculatus, dan P. oly. gacanthus), dan Variola (V. albimarginata). Nama. nama spesies dapat dilihat pada Tabel 1. Hasil identifikasi menunjukkan bahwa tujuh spesies di

Tabel 1. Kisaran panjang total, bobot badan, fekunditas, diameter telur, dan indeks kematangan gonad ikan kerapu yang dikumpulkan mulai Juli 1996 sampai dengan Januari 1997.

Table 1. Ranges of total length, body weight, fecundity, egg diameter, and gonado somatic index (GSI) of grouper collected from July 1996 to January 1997.

\begin{tabular}{|c|c|c|c|c|c|c|}
\hline $\begin{array}{l}\text { Spesies } \\
\text { Species }\end{array}$ & $\begin{array}{l}\text { Jumlah } \\
\text { sampel } \\
\text { No. of } \\
\text { Sample }\end{array}$ & $\begin{array}{c}\text { Panjang } \\
\text { total } \\
\text { Total length } \\
\text { (cm) }\end{array}$ & $\begin{array}{l}\text { Bobot tubuh } \\
\text { Body weight } \\
\text { (g) }\end{array}$ & $\begin{array}{l}\text { Fekunditas } \\
\text { Fecundity }\end{array}$ & $\begin{array}{l}\text { Diameter } \\
(\mu \mathrm{m})\end{array}$ & $\begin{array}{l}\text { IKG } \\
\text { GSI } \\
(\%)\end{array}$ \\
\hline Aetheloperca rogaa & 1 & 41.0 & 1.300 .96 & - & - & $\cdot$ \\
\hline Anyperodon leucogrammicus & 2 & $26.5-30.5$ & $201.53-288.86$ & - & - & - \\
\hline C'ephelopolis argus & 1 & 32.7 & 672.00 & - & $\cdot$ & - \\
\hline C. aurantia & 2 & $18.4-37.4$ & $96.70-843.45$ & $0-241,902$ & $320.07-427.09$ & $0.62-4.23$ \\
\hline C. boenack & 3 & 15.1-17.3 & $58.89 \cdot 66.66$ & ()$\cdot 221,251$ & $246.47-326.30$ & $0-1.08$ \\
\hline C. cyanostigma & 1 & 27.5 & 334.94 & 2,001 & $285.88 \cdot 408.44$ & 0.21 \\
\hline ('. leopardus & 2 & $22.1 \cdot 26.2$ & $129.89 \cdot 253.84$ & $0-4,940$ & $48.59 \cdot 70.91$ & $0-0.44$ \\
\hline C. miniata & 9 & $27.3-35.3$ & $312.10 \cdot 688.35$ & $136,101-207,135$ & $348.21-357.68$ & $0.11-4.52$ \\
\hline C. sexmarulata & 1 & 32.4 & 558.82 & - & - & - \\
\hline C. sonnerati & 3 & $21.5-44.7$ & $125.38-1,613.55$ & $0.2,196$ & $267.74-372.15$ & $0.11-0.83$ \\
\hline Epinephelus areolatus & 15 & $16.4-49.5$ & $55.90 \cdot 1,600.00$ & $14,935-1,298,988$ & $227.83-439.47$ & $0.11 \cdot 6.25$ \\
\hline E. bleekeri & 1 & 34.1 & 416.91 & - & - & $\cdot$ \\
\hline E. corallicola & 3 & $22.7-32.8$ & $163.80 \cdot 482.44$ & $\cdot$ & - & - \\
\hline E. fuscoguttatus & 27 & $24.9-53.5$ & $517.77 \cdot 2,414.54$ & $0.863,767$ & $317.97-388.97$ & $0 \cdot 3.06$ \\
\hline E. merra & 8 & $21.3-32.0$ & $169.10 \cdot 539.99$ & $10,934-34,356$ & $208.82-334.27$ & $0.88-0.97$ \\
\hline E. microdon & 17 & $17.2 \cdot 40.9$ & $68.78-841.06$ & - & - & $\cdot$ \\
\hline E. ongus & 5 & $26.8-46.0$ & $300.95-1,465.94$ & $137,268-690,337$ & $401.60-411.60$ & $0.04-2.28$ \\
\hline E. quoyanus & 5 & $20.0 \cdot 32.3$ & $112.07-158.77$ & $1,360-5,680$ & $64.70-67.59$ & $0.10-1.80$ \\
\hline E. suillus & 9 & $26.0-49.7$ & $257.88-1,800.00$ & - & - & - \\
\hline E. tauvina & 23 & $26.4-66.0$ & $275.00-4,100.00$ & $5,806-706,559$ & $47.60-449.99$ & $0.04-2.44$ \\
\hline Plectropomus lapvis & 2 & $33.3-49.9$ & $425.27 \cdot 1,422.88$ & . & - & - \\
\hline P. leopardus & 9 & $16.5-29.8$ & $54.61-311.20$ & $45,124-45,477$ & $72.85-494.18$ & $1.19-4.80$ \\
\hline P. maculatus & 3 & $31.9-39.0$ & $393.64-666.04$ & - & - & $\cdot$ \\
\hline P. olygacanthus & 2 & $43.7-44.0$ & $864.36 \cdot 1,029.23$ & - & - & $\cdot$ \\
\hline Variola albimarginata & 5 & $28.9-38.7$ & $253.39-535.18$ & $2,839-280,476$ & $76.53-343.79$ & 0.261 .04 \\
\hline
\end{tabular}


antaranya bersifat dominan, yaitu Epinephelus tauvina 23 sampel dan E. suillus (9), E. fuscoguttatus (27), E. microdon (17), E. areolatus (15) dan (9) sampel masing-masing Cephalopholis miniata dan Plectropomus leopardus. Ikan kerapu yang hidup pada berbagai tipe habitat di perairan Filipina dan Indonesia terdapat 46 spesies yang tercakup ke dalam tujuh genera, yaitu Aethaloperca, Anyperodon, Cephalopholis, Cromileptes, Epinephelus, Plectropomus, dan Variola (Kohno et al., 1990; Sunyoto, 1994). Hasil pengumpulan pada penelitian ini tidak ditemukan genus Cromileptes sehingga hanya terdapat enam genera. Genus Cromileptes memiliki satu spesies, yaitu kerapu tikus, C. altivelis. Kerapu ini selain untuk ikan komsumsi, ikan yuwana juga dapat dijadikan ikan hias dan tergolong ikan yang mahal harganya.

Permintaan yang tinggi terhadap jenis ikan ini dapat mengarah pada pengeksploitasian yang sangat intensif yang dapat mengakibatkan kelimpahan sediaan ikan tersebut menipis. Untuk mengurangi tekanan pengeksploitasian terhadap kerapu tikus perlu diupayakan pembudidayaannya karena produksi larva secara massal ikan ini telah berhasil dilakukan di Loka Penelitian Perikanan Pantai (Lolitkanta) Gondol, Bali dan Loka Budidaya Air Payau Situbondo, Jawa Timur.

Produksi total ikan kerapu di Kabupaten Barru tercatat 69,1 ton pada tahun 1991 selanjutnya menurun menjadi 41,7 ton pada tahun 1995 (Anonim, 1995). Dengan adanya kecenderungan penurunan populasi, sudah perlu juga dikembang. kan kegiatan budidaya untuk spesies lain seperti kerapu bulucomba, E. areolatus dalam rangka mengurangi tekanan penangkapan sehingga populasi ikan tersebut di alam tetap lestari

Ditinjau dari kelimpahan yang cenderung menurun di alam yang dihubungkan dengan ukuran panjang yang dapat mencapai $49,5 \mathrm{~cm}$ dengan fekunditas tinggi (1.298.988 butir), maka kerapu bulucomba (E. areolatus) memiliki potensi untuk dibudidayakan di samping kerapu lumpur ( $E$. tauvina), kerapu macan (E. fuscoguttatus) dan kerapu sunu ( $P$. leopardus) yang sudah mulai dibudidayakan. Sedangkan Cephalopholis miniata, E. microdon meskipun sering ditemukan dalam keadaan matang gonad tetapi ukurannya relatif kecil sehingga kurang menunjang untuk dikembangkan sebagai komoditas budidaya (Debus et al. 1989 dalam Yashiro et al. 1993a; DeBruin et al., 1994). Ukuran ikan mempengaruhi jumlah telur yang dapat dihasilkan, di mana ikan yang ber- ukuran lebih berat/panjang berkemungkinan menghasilkan telur dengan jumlah tinggi yang pada gilirannya menghasilkan benih yang cukup untuk menunjang usaha pembesaran.

Pengetahuan akan tingkat-tingkat kematangan gonad ikan diperlukan untuk mengetahui perbandingan antara ikan yang matang gonad dengan yang belum, dari sediaan dalam suatu perairan, apakah ikan sudah memijah atau belum, kapan masa pemijahan dan berapa kali pemijahan dalam satu tahun. Untuk kepentingan budidaya maupun perbenihan perlu dilihat hubungan ukuran ikan dengan tingkat dan indeks kematangan gonad, diameter telur, fekunditas yang erat kaitannya dengan produktivitas dan potensi reproduksi. Data mengenai ukuran ikan, fekunditas, diameter telur dan indeks kematangan gonad setiap spesies ikan kerapu, diberikan dalam Tabel 1. Diameter telur ikan kerapu dapat dihubungkan dengan tingkat perkembangan gonad. Selanjutnya perkembangan ini dapat dijadikan indikasi musim pemijahan dan berapa kali memijah per tahun dengan melakukan pengamatan per bulan. Hasil penelitian ini menunjukkan bahwa musim pemijahan berlangsung sekitar bulan Juli dan November.

Dari 159 sampel ikan kerapu terdapat 30 sampel yang mengandung telur dengan kisaran 1.360. 1.298 .988 butir dan bobot badan (BB) berkisar $58,89.4 .100 \mathrm{~g}$, di mana $C$. boenack telah bertelur pada bobot 58,89-66,66 $\mathrm{g}$ (Tabel 1) sehingga tidak memenuhi kriteria untuk dikembangkan sebagai komoditas potensial budidaya perikanan pantai karena ukuran kecil telah matang gonad yang berindikasi bahwa ikan tersebut memiliki fekunditas rendah dan pertumbuhan lambat. Jumlah telur terendah didapatkan pada E. quoyanus (1.360 butir) di mana kemungkinan sebagian telur yang telah mencapai ukuran $>400 \mu \mathrm{m}$ telah dipijahkan. Menurut Mayunar et al. (1994) induk betina kerapu macan yang baik digunakan untuk pemijahan rangsangan harus memiliki diameter telur 400-500 $\mu \mathrm{m}$ sedangkan pejantan memiliki sperma positif 2 (+2). E. quoyanus memiliki panjang standar maksimal $31 \mathrm{~cm}$ (Heemstra \& Randal, 1993) dan kelimpahan rendah sehingga tidak memenuhi kriteria untuk dikembangkan sebagai komoditas potensial budidaya. Jumlah telur tertinggi (1.298.988 butir) pada E. areolatus $(\mathrm{BB}=1.600 \mathrm{~g}$; $\mathrm{PT}=49,5 \mathrm{~cm}$ ) dan kelimpahannya di alam cukup tinggi sehingga memungkinkan jenis ini dikembangkan sebagai komoditas potensial budidaya perikanan pantai sekaligus menjaga kelestarian- 
nya. Kelompok spesies berikutnya yang memiliki jumlah telur tinggi ( 863.767 butir) adalah kerapu macan, $E$. fuscoguttatus $(\mathrm{BB}=1.600 \mathrm{~g} ; \mathrm{PT}=43,0$ $\mathrm{cm})$. Jumlah tersebut lebih rendah dibanding dengan temuan Mayunar et al. (1991b), yaitu pada pemijahan alami ikan kerapu macan dalam pasangan dengan ukuran induk $(\mathrm{BB}=3,1-6,9 \mathrm{~kg}$; PT $=52.72 \mathrm{~cm}$ ) dapat menghasilkan telur 2,9-5,2 juta butir/ekor. Perbedaan jumlah telur yang dikandung setiap individu dapat dipengaruhi oleh ukuran bobot ikan tersebut. Mayunar et al. (1991a), melaporkan pemijahan alami ikan kerapu macan, dengan ukuran induk $3.6 \mathrm{~kg}$ dapat menghasilkan telur 2-6 juta butir/ekor sedangkan ukuran induk 5-11 kg menghasilkan telur 3,0-9,1 juta butir/ekor. Selain itu, jumlah telur ikan tergantung pada spesies (Shapiro, 1987 dalam Mayunar \& Ahmad. 1994), misalnya E. guttatus (90.000-3.365.000 butir), E. mario (312.0005.735 .000 butir), dan E. diachantus (63.000. 233.000 butir).

Diameter telur ikan kerapu dalam penelitian ini, terbesar ditemukan pada kerapu macan, $P$. leopardus $(\mathrm{BB}=200,15 \mathrm{~g}$; $\mathrm{PT}=25,4 \mathrm{~cm})$ dan memiliki dua kelompok diameter telur $(494,18 \pm$ 82,32 dan $72,85 \pm 6,44 \mu \mathrm{m}$ ) yang mencirikan perkembangan gonad yang dijadikan indikasi multispawning. Berdasarkan Yashiro et al. (1993a) ikan tersebut, tingkat kematangan gonadnya (TKG) tergolong pada kelompok tingkat I dan V. Diameter telur yang memiliki dua kelompok, juga ditemukan pada kerapu lumpur, E. tauvina $(\mathrm{BB}=$ $4.100 \mathrm{~g} ; \mathrm{PT}=66,0 \mathrm{~cm})$, yaitu $410,00 \pm 81,84 \mathrm{dan}$ $90,21 \pm 37,61 \mu \mathrm{m}$, berarti tingkat kematangan gonadnya termasuk I dan $\mathrm{V}$ dan pada spesies yang sama (E. tauvina, $\mathrm{BB}=3.600 \mathrm{~g} ; \mathrm{PT}=64,3 \mathrm{~cm}$ ) didapatkan diameter terkecil, yaitu $47,60 \pm 7,36 \mu \mathrm{m}$ $(\mathrm{TKG}=\mathrm{I})$. Terdapatnya dua kelompok ukuran diameter telur dalam satu individu ikan memungkinkan pemijahan sekurang-kurangnya terjadi sesuai dengan kelompok ukuran diameter telur ikan tersebut dengan puncak musim pada bulan November. Menurut Mayunar \& Ahmad (1994) ikan kerapu macan yang dipelihara dalam bak semen volume $10-30 \mathrm{~m}^{3}$ memijah 3.4 musim per tahun dengan puncak pemijahan pada bulan Agustus dan September.

Indeks kematangan gonad (TKG) tertinggi $(6,25 \%)$ pada $E$. areolatus $(\mathrm{BB}=1.600 \mathrm{~g}$; $\mathrm{PT}=$ $49,5 \mathrm{~cm}$ ) ditemukan dalam bulan Juli, berarti periode pemijahan terjadi sekitar bulan tersebut. Kuo et al. (1988) melaporkan bahwa nilai IKG ikan kerapu ( $E$. fario) sebelum pemijahan dan selama musim pemijahan sebesar $0,12 \%$ pada bulan Februari, meningkat menjadi $0,40 \%$ pada bulan Mei, selanjutnya meningkat menjadi $2,07 \%$ pada bulan Juli. Penentuan tersebut juga berpedoman pada Yashiro et al. (1993a) bahwa ikan kerapu ( $E$. malabaricus), periode pemijahannya (OktoberFebruari) dengan menghubungkan bahwa IKG tertinggi $(5,2 \pm 2,71 \%)$ didapatkan dalam bulan Januari dan terendah bulan Maret $(0,43 \pm 0,025 \%)$. IKG terendah $(0,05 \%)$ ditemukan pada kerapu lumpur $(\mathrm{BB}=3.600 \mathrm{~g} ; \mathrm{PT}=64,3 \mathrm{~cm})$ dalam bulan Juli selanjutnya pada bulan November ditemukan kerapu lumpur $(\mathrm{BB}=4.100 \mathrm{~g}$; $\mathrm{PT}=66.0 \mathrm{~cm})$ memiliki IKG sebesar 2,44\%. Dilihat dari sisi ini, periode pemijahan kerapu tersebut terjadi sekitar bulan November.

\section{KESIMPULAN DAN SARAN}

Di perairan Barru, Parepare dan Pangkep teridentifikasi 25 spesies ikan kerapu yang tercakup ke dalam enam genera (Aethaloperca, Anyperodon, Cephalopholis, Epinephelus, Plectropomus, dan Variola). Di antara enam genera yang ditemukan, dua genera yang memiliki peluang besar untuk dikembangkan sebagai komoditas potensial budidaya dalam penyediaan induk, yaitu Epinephelus (kerapu lumpur, E. tauvina, kerapu macan, E. fuscoguttatus dan kerapu bulucomba, $E$. areolatus) dan Plectropomus (kerapu sunu, $P$. leopardus) karena memiliki ukuran besar $(\mathrm{PT}=$ $49,5-66,0 \mathrm{~cm} ; \mathrm{BB}=1.600,0-4.100,0 \mathrm{~g})$ dengan tingkat kematangan gonad yang tinggi $(2,44-6,25 \%)$ daripada spesies kerapu lainnya dengan puncak musim pemijahan terjadi pada bulan Juni dan November.

Jumlah telur per individu (fekunditas) yang ditemukan mencapai 1.298 .988 butir telur dengan kelompok diameter telur, yaitu dari 47,60 $\pm 7,36 \mu \mathrm{m}$ sampai $494,18 \pm 82,32 \mu \mathrm{m}$, sehingga musim pemijahannya dapat terjadi beberapa kali per tahun (3-4 kali).

\section{UCAPAN TERIMA KASIH}

Disampaikan terima kasih kepada Dra. Rosiana Sabang, Reni Yulianingsih, Andi Sabir, dan Kurnia atas bantuannya dalam menganalisis organ dalam tubuh kerapu. 


\section{DAFTAR PUSTAKA}

Ahmad, T., P. T. Imanto, Muchari, A. Basyarie, P. Sunyoto, B. Slamet, Mayunar, R. Purba, S. Diani, S. Rejeki, S. A. Pranowo, dan S. Murtiningsih. 1991. Operasional Pembesaran Ikan Kerapu dalam Keramba Jaring Apung. Laporan Teknis Balai Penelitian Perikanan Pantai, Maros. 59 hal.

Anonim. 1995. Laporan Statistik Perikanan Sulawesi Selatan. Dinas Perikanan Propinsi Dati I Sulawesi Selatan. Ujung Pandang. 158 hal.

DeBruin, G. H. P., B. C. Russell and A. Bogush. 1994. FAO Species Indentification Field Guide for Fish. ery Purposes. The Marine Fisheries Resources of Srilangka. FAO Fisheries Synopsis No. 125. Roma. 400 pp.

Heemstra, P. C. and J. E. Randall. 1993. Species Catalogue. Vol. 16. Grouper of the World. Annotated and illustrated of the grouper, rockcod, hind, coral grouper, lyretail species known to date. FAO Fisheries Synopsis No. 125. Roma. 382 pp.

Kohno, H.. M. Duray, and P. Sunyoto. 1990. A Field Guide to Grouper at Southeast Asia. Pusat Penelitian dan Pengembangan Perikanan, PHP/KAN/PT No. 14/1990. Jakarta. 26 pp.

Kuo, C-M., Y-Y. Ting, S-L. Yeh. 1988. Induced sex reversal and spawning of the blue spotted grouper, Epinephelus fario. Aquaculture, 74: 113-126.

Mayunar, S. Diani, dan B. Slamet. 1991a. Fekunditas, derajat pembuahan dan derajat penetasan telur ikan kerapu macan, Epinephelus fuscoguttatus yang diberi ransum berbeda. J. Penelitian Budidaya Pantai, 7(2): 1-9.

Mayunar, P. T. Imanto. S. Diani, dan T. Yokokawa. 1991b. Pemijahan ikan kerapu macan, Epinephelus fuscoguttatus. J. Penelitian Budidaya Pantai, 7(2): 15-22.

Mayunar, S. Slamet, dan S. Diani. 1994. Pemijahan ikan kerapu macan, Epinephelus fuscoguttatus dengan rangsangan hormon. J. Penelitian Budidaya Pantai, 10(3): 17-24.

Mayunar dan T. Ahmad. 1994. Pemantauan musim, fekunditas dan kualitas telur ikan kerapu macan, Epinephelus fuscoguttatus dari hasil pemijahan alami dalam kelompok. J. Penelitian Budidaya Pantai, 10(5): 1-12.

Sunyoto, P. 1994. Pembesaran Kerapu dengan Keramba Jaring Apung. PT Penebar Swadaya. Jakarta. 65 hal.

Yashiro, R., J. Kongkumnerd, V. Vatanakul, and N. Ruangpanit. 1993a. Histological changes in gonad of grouper, Epinephelus malabaricus. Grouper Culture. In The Proceeding of Grouper Culture, November 30 - December 1, 1993. Songkhla, $136 \mathrm{pp}$.

Yashiro, R., V. Vatanakul, J. Kongkumnerd, and N. Ruangpanit. 1993b. Variation of sex steroids level in maturing grouper. In The Proceeding of Grouper Culture, November 30 . December 1, 1993. Songkhla, Thailand. $136 \mathrm{pp}$. 